\title{
PROJECTS TO BE FUNDED BY THE EARTHQUAKE COMMISSION RESEARCH PROGRAMME 1997/98
}

\section{EQC PUBLIC GOOD RESEARCH FUNDING}

The EQC funding of public good research, with project topics related to its sphere of activities, was put on a systematic basis from early 1991. Project funding is on a biennial basis. Supported projects for 1991/92 are given in the September 1991 Bulletin of NZNSEE, 1993/94 projects in the June 1993 issue, and 1995/96 in the June 1995 issue.

For each funding round the availability of EQC funds was advertised several months before their allocation. At each round the applications for research project support had budgets which totalled several times the available funds. Within EQC budget constraints, the most worthy and appropriate projects have been funded.

The major input to the selection of research proposals for funding has been made by a panel of seven experts set up by the EQC Research Foundation. The members of the panel have been chosen to cover research fields related to EQC activities, and for their knowledge of the progress and needs of these research fields in New Zealand.

\section{ES 227 Two-Dimensional Site Effects in Wellington - Similarities to Kobe University of Canterbury - J B Berrill}

Superficially at least there seem to be strong parallels between the seismological and geotechnical conditions at Wellington and Kobe. Both have strike-slip fault systems capable of generating earthquakes of around magnitude 7, both have extensive areas of reclaimed land, and both have large numbers of vulnerable reinforced-concrete structures. The Hyogo-ken-Nambu earthquake was characterised by a narrow band of intense damage parallel to but about $800-1000 \mathrm{~m}$ south of the fault system. This band of intense shaking can be explained by twodimensional site effects. In broad terms, the small vertical offsets accompanying horizontal movements on the fault have left stiff material on one side of the fault but soft sediments to a depth of about one kilometre on the other. Thus waves reach the surface earlier on the stiff side; the diffracted field from the stiff side into the soft side has travelled out a distance $-800 \mathrm{~m}$ or so in the case of Kobe - before the direct wave arrives on the soft side. The constructive superposition of the two waves yields a narrow region of intense shaking. At first sight, the necessary conditions appear to exist in Wellington. The main aim of this project is to make a 2-D study of the Wellington situation to see whether a similar concentration of intense shaking can be expected.
ES 230

\author{
Revised National Seismic Hazard Model \\ Institute of Geological \& Nuclear Sciences Ltd - \\ James Hengesh
}

Recent advances in amount and quality of paleoseismic, GPS and historical seismicity data provide new information on the locations and rates of crustal deformation in New Zealand. These updated data sets, and a newly developed New Zealandspecific ground motion attenuation relationship were used to estimate seismic hazards for the Hawke's Bay and Canterbury regions, and have led to important revisions from previous estimates of seismic exposure. Comparison of the revised hazard calculations with the commonly used model of Smith and Berryman (1992) suggest that differences in the findings result primarily from the type of input parameters and attenuation relations used. The existing seismic hazard models, Smith and Berryman and QuakeCheck, draw on models of distributed seismicity only, and do not use line sources to model faults, and geodetic data to model blind or areal seismic source zones in the hazard computation. Furthermore, the methodology used in Smith and Berryman calculations are based on techniques that are more than 10 years old.

This proposal seeks to develop a fully integrated national seismic hazard model to estimate earthquake intensity and strong ground motion (pga and spectral accelerations) for return periods or probabilities of exceedence appropriate for use in developing revised code requirements, seismic design criteria, or estimating potential earthquake losses at a national level. The proposed model would integrate fault slip-rate, historical seismicity, and geodetic data to define seismic source zones and earthquake recurrence parameters for input to the hazard calculation. The final hazard model would have the capability to produce maps of MM intensity, peak ground acceleration (pga), and frequency dependent spectral accelerations.

\section{S\&G 237 Paleoseismic Investigation of the Ashley Fault, North Canterbury \\ University of Canterbury - Jarg R Pettinga}

The $4.5 \mathrm{~km}$ Ashley fault trace immediately west of Rangiora township, North Canterbury, disrupts late Pleistocene an Holocene terraces of the Okuku River. Preliminary field mapping indicates the fault is a southward directed thrust with vertical throws of 1-4 $\mathrm{m}$ across a late Pleistocene loess capped aggradation terrace surface, and up to $1.5 \mathrm{~m}$ across a Holocene River terrace (Cowan, 1992). Based on this, Cowan inferred 2 rupture events since at least the late Pleistocene. However, no specific paleoseismic data are available for the Ashley fault, and the terraces offset by the fault have been dated only by relative chronologies.

The proximity of the Ashley fault to urban areas such as Rangiora, Kaiapoi and metropolitan Christchurch makes this proposed paleoseismic investigation highly pertinent with respect to earthquake hazard assessment of the North Canterbury region. 
S\&G 247 Earthquake-Generating Potential of Wellington's "Second Order" Faults Institute of Geological \& Nuclear Sciences Ltd $J$ G Begg

Understanding of seismic hazard in Wellington is dependent upon evaluation of the return periods and magnitude estimates of major nearby earthquake sources. In Wellington five major surficial earthquake sources have been identified and their characteristics estimated. These are, from west to east, the Wairau, Shepherds Gully/Pukerua, Ohariu, Wellington and Wairarapa faults.

For many years, an anastomosing network of "second order" faults have been identified in the area, and while they were formerly considered to be uniformly inactive, recent geological mapping suggests that at least some of them may still be active and should be considered potential earthquake sources. "Second order" faults are defined as those that are truncated by the "principal faults", and many in the Wellington area trend NNE. Proving activity is difficult; some evidence may have been obscured through 150 years of surface modification, particularly in built-up areas; many of the faults are found in areas without Quaternary deposits, making proof of activity impossible. Study of aerial photographs of Whitemans Valley, east of Upper Hutt, has identified a landform that may be a fault trace on one of these "second order" faults, and offers the rare opportunity to evaluate the activity of a representative of this network.

Trenching across this landform will begin to place constraints on the hazard posed by this previously unrecognised group of potential earthquake sources. Such constraints are a necessary first step towards incorporating these faults into seismic hazard models and earthquake risk models of the region.

\section{S\&G 248 Earthquake Hazard Characterisation of the Tararua Section of the Wellington Fault Institute of Geological \& Nuclear Sciences Ltd - Kelvin Berryman}

Rupture of the Wellington-Hutt Valley segment of the Wellington fault (Berryman, 1990; Van Dissen et al., 1992) is the usual scenario for insurance industry Probable Maximum Loss (PML) earthquake models for New Zealand. Recent studies by Van Dissen and Berryman (1996) and Robinson and Benites (1996-submitted) have demonstrated, from two points of view, that rupture of one of the faults in the Wellington region has not, and probably will not, result in rupture of an adjacent fault. However, Robinson and Benites have shown in their modelling studies that along-strike triggering of another segment of the same fault is a realistic possibility for the Wellington region faults. Thus, rupture of the Wellington-Hutt Valley segment of the Wellington fault might be accompanied by, or triggered by, rupture of the along-strike Tararua section of the fault. This scenario would result in different PML models.

Although in difficult terrain, the location of the Wellington fault in the Tararua Ranges is reasonably well-known (Lensen, 1958), and there have been some detailed studies of the fault just to the north of the Tararuas (Beanland and Berryman 1991). Specific ground studies within the ranges have not been conducted however, and these would form the basis of this project. In similar terrain to the Tararua Ranges along the Alpine fault in northern Fiordland significant detail of the fault rupture history has been obtained (Hull and Berryman, 1986; Sutherland and Norris, 1995) so there can be some optimism that similar results could be obtained from detailed study of the Wellington fault in the Tararua Ranges.

\section{S\&G 249 Evaluation of Wells and Coppersmith (1994) Earthquake and Fault Relationships in the New Zealand Context \\ Institute of Geological \& Nuclear Sciences Ltd - Kelvin Berryman}

The empirical relationships presented by Wells \& Coppersmith (1994) that relate various fault parameters to earthquake magnitude have become a cornerstone of geological assessment of earthquake hazard. These relationships are based on a compilation of faulting parameters associated with large historical earthquakes, and allow estimates of future earthquake magnitude from characteristic surface fault displacement or trace length. However, other workers (eg, Wesnousky, 1988, 1990; Stirling et al., 1996) have noted that cumulative total slip on a fault and slip rate are also important parameters that may govern fault complexity and thus may influence rupture length and moment release. Thus, total fault slip, geometric complexity, and fault slip rate, as well as fault type (the main disciminant used by Wells and Coppersmith), are all possible determinants of fault parameter and earthquake magnitude relations.

Preliminary appraisal of limited historical and paleoseismological data from New Zealand do not match the mean regressions of the Wells and Coppersmith relations (eg, Beanland et al, 1989; Berryman 1990; Cowan 1991).

This proposal seeks to compile available New Zealand data that relates earthquake magnitude to surface faulting parameters, slip rate, and total slip, and to analyse the Wells and Coppersmith database, investigating the possibility of regional bias and that other factors may control the relationships between earthquake magnitude and faulting parameters. The result will improve methods for estimating earthquake hazard in New Zealand.

\section{S\&G 254 A Seismological and Engineering Study of the 1942 Wairarapa Earthquakes \\ Institute of Geological \& Nuclear Sciences Ltd- Gaye Downes}

In 1942 the Wairarapa and Wellington districts were strongly shaken and extensively damaged by three large magnitude earthquakes (June 24, Ms7.2; Aug 01, Ms7.0; Dec 02, Ms6.0). They are poorly documented and have been little investigated. Critical examination of historical descriptions of the earthquakes from newspapers and other archival sources will result in detailed accounts of their effects, and will allow the drawing of isoseismal maps. These are presently unavailable or inadequate. Reinterpretation of seismograms from New Zealand stations should provide constraints on the epicentres of the main events and the epicentres and magnitudes of larger aftershocks. Understanding of the tectonic significance of the earthquakes can then progress. 
The 1942 June and August earthquakes are good examples of "large distant shallow earthquake" scenario model events for microzone effects in Wellington. For this reason it is particularly important to determine, in detail, building damage in Wellington, as well as in the highest intensity area.

\section{S\&G 256 Dense Array Analysis of Ground Motions in a Sedimentary Basin \\ Victoria University of Wellington - $J J$ Taber}

The amplification of ground motion within sedimentary basins has been a major factor in the damage distribution from some earthquakes, but given the variability of amplification from event to event, the prediction of future amplifications is still difficult. Prior studies have shown a correlation between the degree of amplification and the spatial coherence of seismic waves entering the basin. The purpose of this project is to study the effect of the spatial coherence of waves on the amplification pattern in a sedimentary basin. We will use data already collected from a dense weak-motion array that was deployed in Wainuiomata. Over 80 earthquakes have been recorded at up to 20 sites with a station spacing of $25-100 \mathrm{~m}$. The basic amplification analysis (using soft site/rock site spectral ratios) and $3 \mathrm{D}$ computer modelling using simple plane waves will have been completed under a FRST contract before the start of this project. 3D modelling of random waves will be carried out as part of this project. The random modelling is required to test the suggested correlation between the amplification and spatial coherence.

\section{S\&G 259 A Consistent Geological-Seismological Model for Earthquake Occurrence in New Zealand Victoria University of Wellington - Euan Smith}

To develop a method for modelling NZ seismicity so that there is consistency between the observed historical seismicity and the geological record of fault activity. It will be based on well established laws of earthquake occurrence - the Gutenberg \& Richter law of magnitudes, Omori's law of aftershocks, the nearPoissonian distribution of earthquakes in space, and earthquakesize scaling laws that relate fault-length and fault-slip to seismic moment and magnitude. It will also use ideas recently developed by several authors based on time-varying rates of activity, because there is a clear inference from the mismatch between geological and seismological models for the rate of occurrence of large earthquakes that rates vary with time.

An important factor that will be considered in developing the method will be focal depth, which has hitherto been very simply treated in NZ seismicity models because of the unavailability, prior to 1990, of good data about the depths of shallow earthquakes. We will distinguish between the seismicity occurring within and above the subducting plates of the North Island-Marlborough. It is the shallower seismicity that must be related to the geological data.

The product of the research will be methodology for establishing regionally $(3-\mathrm{D})$ varying seismicity models that are consistent with both historical seismicity and geological data. The method will be tested on NZ data from the central South Island, northwest Nelson, Marlborough and the Wellington region.
S\&G 262 Paleoseismicity, Rates of Active Deformation, and Structure of the Lake Jasper Pull-apart Basin, Awatere Fault, New Zealand Victoria University of Wellington - Timothy A Little

The little-studied Awatere Fault which last moved in 1848 during a Ms7.5+ earthquake, may link with the Wellington Fault beneath Cook Strait, and is a likely source of damaging earthquakes to the capital city (1848 produced Mm8). Bounded on two sides by active scarps and filled with organic sediments, Lake Jasper (a km-scale feature near Blenheim) is a superb site to study:

(1) frequency and magnitudes of past earthquakes on the Awatere Fault,

(2) late Quaternary slip rates,

(3) geodetic strain accumulation across the fault, and

(4) mechanism of slip transfer across strike-slip fault bends, their depth extent, and possible role as seismogenic asperities.

We propose for 1997-1999:

(1) trenching the scarp (collaborative with R Van Dissen, IGNS) coring and stratigraphic analysis of adjacent lake sediments,

(2) ${ }^{14} \mathrm{C}$ and thermoluminescence dating of critical markers, including offset stream channels and terrace edges,

(3) reoccupation by GPS of fault monitoring network established over Lake Jasper in 1971 (collaborative with J Beaven, IGNS), and

(4) precise EDM-theodolite mapping of terrace surface displacements, and seismic refraction studies to resolve that basin's depth and 3-D structure.

\section{S\&G 263 Earthquake Hazard Assessment of a Newly Discovered Active Strike-slip Fault in Horowhenua Massey University - Alan Palmer}

In 1995, reconnaissance field work in the Horowhenua district led to the important discovery of a previously unknown, and therefore unmapped, major, active, right-lateral strike-slip fault that extends north-northeastward from near Te Horo to near Palmerston North. This "new" fault passes within $10 \mathrm{~km}$, or closer, of Waikanae, Otaki, Levin, Shannon and Palmerston North; it is the closest known active fault to the later four. The fault appears to be the northern, along strike, extension of the Ohariu fault, and has thus been informally termed the Northern Ohariu fault. It has a length of at least $50-60 \mathrm{~km}$, but is northern termination is, as yet, poorly defined.

Based on faulted-unfaulted relationships of alluvial terraces that cross the fault, and the ages estimated for these terraces based on soil development, it is certain that the fault has ruptured more than once in the last $10,000-20,000$ years, that the most recent movement on the fault occurred within the last 5,000 years, and that the fault has not moved within the last several hundred years.

However, knowledge of the fault's slip rate (though it is most likely less than $4-5 \mathrm{~mm} / \mathrm{yr}$ ), and its maximum magnitude earthquake recurrence interval and size are unknown (though it is probably capable of generating magnitude 7 to 8 earthquakes). 
This project seeks to better quantify the rupture parameters of this fault. We intend to do this by the study (detailed geological and soils mapping) of approximately six previously identified sites on the fault where there is the potential to estimate the fault's slip rate, surface rupture recurrence interval, and singeevent displacement size. We also intend to define the fault's northern termination (and thus its length and estimated maximum magnitude earthquake).

\section{S\&G 268 Ash Predictions, How Successful were they?} Institute of Geological \& Nuclear Sciences Ltd Tony Hurst

Before the 1995/96 Ruapehu eruption, IGNS had produced a computer program for doing rapid predictions of likely ash fallout from a volcanic eruption of a certain size. This program was used during the 1995 and 1996 eruptions, using wind forecasts from the New Zealand Meteorological Service.

To improve future predictions in this area all available information will be gathered on what ash actually landed more than a few kilometres from Ruapehu and will be compared to forecasts made at the time to see how accurate the model was, and whether any changes in it would give improved results in future eruptions.

GE 276

SASW Measurements for the Calculation of
Site Amplification
Opus International Consultants - Alan Sutherland
and Tim Logan

The site parameters required for the calculation of site amplification using programs such as SHAKE and FLAC, are the shearwave velocities and damping ratios for each layer down to bedrock. The Spectral Analysis of Surface Waves (SASW) method is a state-of-the-art technique applicable to the determination of shearwave profiles at sites with layers of varying stiffness. We aim to evaluate the use of SASW as a low cost method of determining shearwave velocities as an input for the calculation of site amplification. The characteristics of the soil closest to the surface have the greatest impact on the site amplification. SASW is therefore well suited for such studies since it can provide a shearwave velocity profile to a depth of 30 to 40 metres.

\section{Performance of External Beam-Column Joints in Ductile Concrete Frames \\ University of Auckland - L M Megget}

Beam-column joints play a key role in the seismic performance of ductile concrete frames. However, a number of aspects of their behaviour are not well understood. In the proposed project these will be examined in a series of tests and analyses on external beam-column sub-assemblies. This forms part of a wider project with the internal beam-column joints being studied in a parallel project at the University of Canterbury.

The particular aspects which it is planned to investigate at Auckland include:

- the effect of beam elongation on the joint zone;

- the change in performance arising from different detailing, such as the use of end plates, spread beam reinforcement and different ways of anchoring the longitudinal beam bars.

- the influence of different axial load levels in the column.

SE 292

\author{
Development of a Design Procedure for \\ Uplifting Tanks \\ University of Auckland - B J Davidson
}

Unanchored storage tanks tend to lift off their bases during large earthquakes due to the overturning forces caused by the hydrodynamic pressures generated on the walls and base. This uplift has caused damage and loss of contents to tanks in past earthquakes. Previous studies at the University of Auckland using static analysis procedures have shown that the stiffness of the foundation has a large influence on the performance of these tanks. The proposed research will extend this work with nonlinear time history finite element analyses. These investigations will include the examination of the influence of soil-structure interaction, slosh wave resonance, membrane action in the base plate, and plastic yielding of the wall-floor junction.

This work will be able to proceed primarily because of access to a "super computer" recently obtained by the School of Engineering at Auckland.

It is intended that the results obtained can be used to develop a simplified design approach which can be incorporated into the NZNSEE "Seismic Design of Storage Tanks" report form.

\section{SE 294 Seismic Design and Behaviour of Reinforced Concrete Beam-Column Joints University of Canterbury - J I Restrepo}

In the design of reinforced concrete frames of buildings using capacity design, beam-column joints are required to be stronger than the selected regions in the members of the frames that are detailed for ductility to concentrate plastic deformations and dissipate energy during a severe earthquake.

The design of beam-column joints in New Zealand follows the macro-model proposed by Park and Paulay in 1974, which is based on a diagonal concrete strut and a parallel truss mechanism of shear transfer. The model has been refined over the years and current recommendations in the Concrete Structures Standard NZS 3101:1995 reflect the state-of-the-art in this area. Unlike flexural strength, and even shear strength, in reinforced concrete beams and columns, the shear strength of beam-column joints cannot be assessed with accuracy at present due to the lack of complete understanding of the interaction between the different variables influencing the strength.

Current design recommendations indicate that axial compression in the columns enhances the shear transfer mechanism through the diagonal strut on and reduces the need for joint hoops to resist shear. Due to the inherent difficulties of testing beamcolumn subassemblages under moderate levels of axial compression, and to the belief that the most severe condition for beam-column joints is when axial load is absent, a very limited number of seismic load tests have been conducted in the world in this type of joints. The lack of test results does not permit a 
thorough validation of the Concrete Structures Standard recommendations over the range of axial load levels often found in typical multistorey buildings. However, recent theoretical work suggest that when the axial compression in columns is moderate or high NZS 3101:1995 recommendations may not be appropriate.

With the advent of Grade 500 reinforcing steel, to be released into the market in early 1997, the problem of anchoring bars in beam-column joints may become critical if an acceptable hysteretic performance is to be achieved and if bond failure is to be delayed. This problem is more relevant when the primary earthquake resisting system is allocated to perimeter frames. One way to make efficient use of Grade 500 reinforcing steel is to reinforce the beams with distributed longitudinal reinforcement, instead of lumping top and bottom bars. Limited research in this area was conducted at the University of Canterbury in the 1980s and further testing is required.

The aim of the proposed work is to develop analytical tools and carry out testing on a range of reinforced concrete beam-column subassemblages that allows rational design recommendations to be made and also to facilitate the assessment of the seismic behaviour of beam-column joints of older buildings. The Universities of Canterbury and Auckland have discussed ways of collaborating in this project.

\section{SE 296 Seismic assessment and retrofit of existing reinforced concrete building structures University of Canterbury - $R$ Park}

Typical early reinforced concrete building structures, designed according to building codes prior to about 1.970, have reinforcing details which are adequate for gravity and wind loads but may not be adequate for earthquake loads. Earthquake design codes before about 1970 did not specify capacity design nor detailing procedures which ensure adequate strength and ductility in the event of a major earthquake.

The aim of the proposed research is to conduct inelastic dynamic analyses of further typical existing reinforced concrete building structures which were designed to early building codes, and to conduct further seismic load tests on subassemblages containing a range of poor reinforcement details typical of many early structures to obtain additional information for seismic assessment procedures. The investigation of methods for retrofitting such buildings will also be continued. 